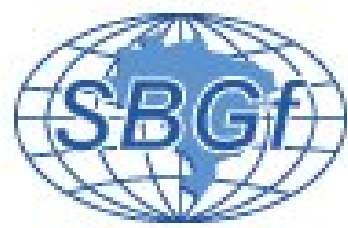

\title{
MÉTODOS ACÚSTICOS PASSIVOS INTERFEROMÉTRICOS APLICADOS À OB- TENCÃ̃O DE DADOS OCEANOGRÁFICOS
}

\author{
Pessek K., Chaves, A. H. S, Guimarães L. G., Parente C. E., LIOc COPPE-UFRJ
}

Copyright 2012, SBGf - Sociedade Brasileira de Geofisica Este texto foi preparado para a apresentação no V Simpósio Brasileiro de Geofísica, Salvador, 27 a 29 de novembro de 2012. Seu conteúdo foi revisado pelo Comitê Técnico do V SimBGf, mas não necessariamente representa a opinião da SBGf ou de seus associados. É proibida a reprodução total ou parcial deste material para propósitos comerciais sem prévia autorização da SBGf.

\section{RESUMO}

Em geral, o som em uma banda de frequência larga assossiada a ruídos de cavitação de navios pode se propagar por mecanismos de interferência a longa distância entre a superfície e fundo do mar. Tal fenômeno está assossiado a modos normais discretos de vibração do campo sonoro no oceano. Neste processo de propagação a onda carrega informações sobre propriedades do fundo e da coluna d'água. Numa tentativa de extrair estas informações utiliza-se a técnica de decompor a intensidade acústica em um espectograma. No espectograma o comportamento das estruturas de interferência pode ser quantificado por uma grandeza típica de cada guia de onda denominada invariante adiabático $\beta$. Neste trabalho utilizando esta técnica mostramos, tanto teórica quanto experimentalmente, que existe um conjunto finito de modos que podem alcançar longas distâncias entre fonte e receptor que podem ser utilizados nesta tarefa.

\section{INTRODUÇÃO}

Em águas rasas o ambiente submarino se comporta como um guia de ondas para o campo sonoro (Chuprov, 1982). Esse som aprisionado no guia gera um um padrão típico de interferências (Fig.1) no qual é possivel extrair informações geoacústicas e oceonográficas. Algumas das características desse tipo de guia de ondas foram previamente discutidos em (Chaves et al., 2011). Ruídos gerados por navios no mar possuem um espectro com várias frequências e diferentes amplitude que variam ao longo do tempo. Muitas vezes, a associação desses ruídos a ambientes em águas rasas geram modos normais na propagação do campo sonoro. Ao serem processados esses ruídos ou sinais produzem em espectogramas um padrão coerente denominado estrutura de interferências ou estrias que são robustas características do guia de ondas, onde estão embutidas informações a respeito do meio de propagação. Tais estruturas de interferência do campo de pressão já são a bastante tempo estudadas à luz da teoria dos invariantes adiabáticos de guias de ondas (Chuprov, 1982; D'Spain e Kuperman, 1999; Jensen et al., 2011; Sell e Culver, 2011; Harrison, 2011; Rouseff e Spindel, 2002) que permite associar ao parâmetro denominado $\beta$ um cojunto de informações ambientais desse guia de ondas.

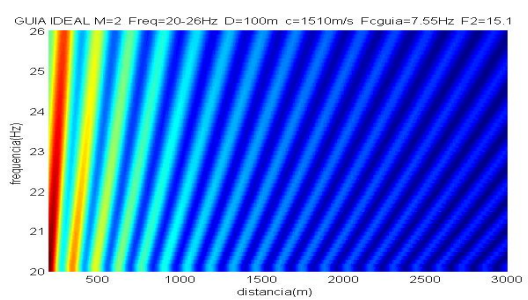

Figura 1: Estruturas de interferências em um espectograma

Nas seções seguintes discutiremos brevemente sobre a teoria dos invariantes adiabáticos bem como aplicá-la ao problema de obtenção de estimativas do alcance acústico em um ambiente marinho real.

\section{TEORIA}

A propriedade do guia de ondas acústico em manter um padrão de interferência robusta em várias condições é uma consequência da relação entre a variação da velocidade de grupo em relação à velocidade de fase para um grupo de modos normais no guia (Jensen et al., 2011). Podemos ver isto observando que a intensidade sonora é proporcional a raiz média quadrática da pressão $I=\left\langle P^{2}\right\rangle / \rho c$ onde $\rho$ é a densidade e $c$ a velocidade do som. No caso de um guia de ondas e uma fonte sonora emitindo uma intensidade $I_{0}$, a intensidade $I$ do som propagante ao longo do guia pode ser decomposta em modos normais discretos da seguinte forma:

$$
I(r, \omega) \equiv I_{0} \sum_{n} B_{n}^{2}+2 \sum_{m \neq n} B_{m} B_{n} \cos \left(\Delta k_{m n}(\omega) r\right)
$$

Onde $\Delta k_{m n}=k_{r m}-k_{r n}$ é a diferença entre os pares de números de onda horizontais, $B_{m, n}=r^{-1 / 2} A_{m, n}$ são as amplitudes dos modos. Além disso, no gráfico de 
distância versus frequência num receptor (Fig.1), a linha que representa o padrão de interferência possui mesma intensidade $I(r, \omega)=$ const. de modo que:

$$
\frac{d \omega}{d r}=-\frac{\partial I}{\partial r} / \frac{\partial I}{\partial \omega}
$$

Portanto, derivando a Equação 1 em relação a distância e frequência:

$$
\begin{aligned}
& \frac{\partial I}{\partial r}=-\omega \sum_{m, n} B_{n} B_{m}\left(\frac{1}{v_{m}}-\frac{1}{v_{n}}\right) \sin \left(\Delta k_{m n} r\right) \\
& \frac{\partial I}{\partial \omega}=-r \sum_{m, n} B_{n} B_{m}\left(\frac{1}{u_{m}}-\frac{1}{u_{n}}\right) \sin \left(\Delta k_{m n} r\right)
\end{aligned}
$$

Sendo as velocidades de fase e grupo modais dadas respectivamente pelas equações (Jensen et al., 2011):

$$
\begin{gathered}
v_{n}=\frac{\omega}{k_{r n}} \\
u_{n}=\frac{d r}{d t}=\frac{d \omega}{d k_{r n}}
\end{gathered}
$$

Além disso, para um grupo de modos podemos expressar o inverso de cada velocidade de fase e grupo em uma expansão em série de Taylor em torno de uma velocidade média $\left\langle S_{p}>^{-1}\right.$, que são analogamente definidos como vagarosidade de fase $S_{p}$ e grupo $S_{g}$ :

$$
S_{g}^{n} \approx<S_{g}>+\frac{d S_{g}}{d S_{p}}\left(S_{p}^{n}-<S_{p}>\right)
$$

Inserindo estes resultados em Eqs.3 e 4 obtemos que:

$$
\frac{\partial r}{\partial \omega}=-\frac{r}{\omega} \frac{d S_{g}}{d S_{p}}
$$

Sendo assim, o "invariante" $\beta$ pode ser escrito em termos destes parâmetros como (Chuprov, 1982):

$$
\frac{1}{\beta}=-\frac{d S_{g}}{d S_{p}}=-\left(\frac{v}{u}\right)^{2} \frac{d u}{d v}
$$

Ou melhor, substituindo (Eq.8) em (Eq.9) também temos que,

$$
\beta=\frac{r d \omega}{\omega d r}
$$

De onde podemos explicitamente ver que o invariante do guia de ondas denominado $\beta$ é um parametro útil para entender o comportamento dos padrões de interferência, uma vez que ele se relaciona diretamente com a inclinação das estrias representadas em espectogramas.

\section{RESULTADOS}

A importância do densenvolvimento da teoria do guia de ondas reside no fato que para situações fora do guia ideal temos que levar em consideração a variação do parâmetro $\beta$ que é função de parâmetros geométricos, propriedades geoacústicas e oceanográficas do guia de ondas assim como profundidades da fonte e receptor. Em geral o parâmetro $\beta$ pode variar de 1 a -3 . Neste trabalho usamos $\beta=1$ que correponde a um o guia ideal com refletores perfeitos (Rouseff e Spindel, 2002), perfil de velocidade constante e igual a $1500 \mathrm{~m} / \mathrm{s}$ e profundidade da coluna de água de 60 metros. A intensidade normalizada de cada par de modos no espectograma (Fig.2) é traçada e verificamos nas maiores intensidades a estrutura de interferência.

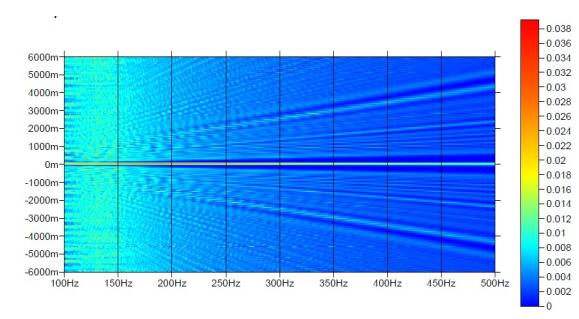

Figura 2: Espectograma de intensidade normalizada

Segue de (Eq.1) que os máximos de interferência ocorrem para distâncias $R_{m n}$ tal que:

$$
\Delta \kappa_{m n} R_{m n}=2 \pi
$$

para o guia ideal temos que o número de onda vertical é dado por (Jensen et al., 2011):

$$
\kappa_{m}=\sqrt{(2 \pi f / c)^{2}-(m \pi / H)^{2}}
$$

que resulta:

$$
r_{m, n} \equiv \beta R_{m, n}=\frac{8 H^{2}}{c\left(m^{2}-n^{2}\right)} \beta f
$$

onde $\mathrm{H}$ é a profundidade máxima do guia , $c$ é a velocidade do som, $f$ a frequência $e, m$ e $n$ a ordem dos modos. Portanto, observa-se da equação acima que modos adjacentes estão associados as estrias de maior inclinação e estes se propagam em grandes distâncias.

\section{DISCUSSÃO E CONCLUSÕES}

Verificando o comportamento assintótico (Fig.3), notamos que os pares de modos de baixa ordem nos fornecem maiores alcances ou distâncias para o caso do guia ideal com refletores perfeitos, perfil de velocidade do som constante, e $\beta=1$. Para o caso de dados fora do guia de ondas ideal temos que levar em consideração a variação do invariante $\beta$ que está associado as características oceonográficas e geoacústicas do ambiente de propagação. 


\section{AGRADECIMENTOS}

\section{REFERÊNCIAS}

Chaves, A., Pessek, K., Guimarães, L., e Parente Ribeiro, C., 2011, Shalow water acoustic propagation at arraial do cabo, brasil: Twelfth International Congress of the Brazilian Geophysical Society.

Chuprov, S. D., 1982, Intererence structure of sound field in a layered ocean:, current stateModern Acoustics and Signal Processing edited by L. M. Brekhovkikh and I. B. Andreeva (Nauka, Moscow).

D'Spain, G. L., e Kuperman, W. A., 1999, Application of waveguide invariants to analysis of spectrograms from shallow water environments that vary in range and azimuth: The Journal of the Acoustical Society of America, 106, no. 5, 2454-2468.

Harrison, C. H., 2011, The relation between the waveguide invariant, multipath impulse response, and ray cycles: The Journal of the Acoustical Society of America, 129, no. 5, 2863-2877.

Jensen, F., Kuperman, W., Porter, M., e Schmidt, H., 2011, Computational ocean acoustics:, Modern Acoustics and Signal Processing Springer.

Rouseff, D., e Spindel, R. C., 2002, Modeling the waveguide invariant as a distribution AIP Conference Proceedings, 621, no. 1, 137-150.

Sell, A. W., e Culver, R. L., 2011, Waveguide invariant analysis for modeling time-frequency striations in a range-dependent environment: The Journal of the Acoustical Society of America, 130, no. 5, EL316EL322. 